\title{
PERENCANAAN BISNIS PENUKARAN MATA UANG ASING "FORRENCY"
}

\author{
Denis Wijaya \\ Program Studi Magister Manajemen Universitas Tarumanagara \\ freedom_ooriser@yahoo.com
}

\begin{abstract}
Foreign exchange is a service to exchange foreign currency, given to people or company who wants to buy or sell a currency by money changer. Jakarta as the capital city of Indonesia is one of the promising regions to build a foreign exchange business because many companies used foreign currencies for transactions, large numbers of foreign currencies need in similar companies, Jakarta has many tourist destinations, and local residents' activity that travel to other country. Also, development in technology encourages companies to innovate in improving services. To prove that this business is feasible, a business feasibility analysis is needed to selected aspects, which is environmental aspect, legal aspect, technical and technological aspect, HR (Human Resources) aspect, marketing aspect, and financial aspect. Environmental aspect is feasible because of its strategic and promising location. Legal aspect is feasible because the needs of documents and licensing requirements that are met. The technical and technological aspect is feasible because of the innovation in service. HR aspect is feasible because of the organizational structure and readiness of skilled workforces. Marketing aspect is feasible because of the market of the business. Financial aspect is feasible because of indications of valuation to produce a foreign exchange business.
\end{abstract}

Abstrak: Kegiatan penukaran mata uang asing adalah pelayanan untuk menukarkan mata uang asing yang diberikan kepada orang atau perusahaan yang ingin membeli maupun menjual suatu mata uang asing oleh Money changer. Jakarta sebagai Ibukota negara Indonesia merupakan salah satu kawasan yang menjanjikan untuk membangun bisnis penukaran mata uang asing karena banyak perusahaan yang menggunakan mata uang asing untuk bertransaksi, kebutuhan mata uang asing di perusahaan sejenis dalam jumlah besar, Jakarta memiliki banyak tempat wisata, dan kegiatan penduduk setempat yang melakukan perjalanan keluar negeri. Selain itu, perkembangan teknologi juga mendorong perusahaan untuk melakukan inovasi dalam peningkatan pelayanan. Untuk dapat membuktikan kelayakan bisnis ini dibutuhkan analisa kelayakan bisnis terhadap aspek-aspek terpilih, yaitu aspek lingkungan, aspek hukum, aspek teknis dan teknologi, aspek SDM (Sumber Daya Manusia), aspek pemasaran, dan aspek keuangan. Pada aspek lingkungan dikatakan layak karena lokasi yang strategis dan menjanjikan. Aspek hukum dikatakan layak karena kebutuhan dokumen-dokumen dan persyaratan perizinan yang terpenuhi. Aspek teknis dan teknologi dikatakan layak karena adanya inovasi dalam pelayanan. Aspek SDM dikatakan layak karena struktur organisasi dan kesiapan tenaga kerja yang terampil. Aspek pasar dan pemasaran dikatakan layak karena adanya pasar untuk bisnis. Aspek keuangan dikatakan layak karena indikasi penilaian untuk menghasilkan bisnis penukaran mata uang asing.

Keywords: Foreign Exchange, Money Changer, Innovation, Environmental Aspect, Legal Aspect, Technical and Technological Aspect, HR Aspect, Marketing Aspect, and Financial Aspect. 


\section{PENDAHULUAN}

Kegiatan penukaran mata uang asing adalah pelayanan untuk jasa tukar-menukar mata uang asing yang diberikan kepada orang atau perusahaan yang ingin membeli maupun menjual suatu mata uang asing. Money changer merupakan suatu kegiatan wirausaha dimana pelaku usaha melayani transaksi penukaran mata uang asing dan memperoleh keuntungan dari jasa itu. Money changer merupakan KUPVA (Kegiatan Usaha Penukaran Valuta Asing) bukan bank memiliki pasar yang sangat potensial, terutama di Jakarta sebagai ibukota negara Indonesia, karena banyaknya perusahaan di kota ini yang melakukan transaksi jual-beli barang maupun jasa ekspor atau impor dengan perusahaan yang berbasis di luar negeri dengan menggunakan mata uang asing. Jakarta juga memiliki banyak tempat wisata sehingga banyak menarik wisatawan asing datang ke Jakarta. Selain itu, penduduk setempat pun juga memiliki kegiatan perjalanan keluar negeri dengan tujuan baik itu untuk berlibur, ibadah, pendidikan, dinas pekerjaan maupun bisnis. Berdasarkan data Kementerian Pariwisata (KEMENPAR), jumlah wisatawan asing yang datang ke Jakarta melalui Bandar Udara Internasional Soekarno-Hatta mengalami peningkatan dari tahun ke tahun.

Tabel 1 Jumlah Wisatawan Asing yang Datang ke Jakarta

\begin{tabular}{|l|l|}
\hline Tahun & Jumlah Wisatawan \\
\hline 2014 & $2,246,437$ \\
\hline 2015 & $2,455,279$ \\
\hline 2016 & $2,603,195$ \\
\hline $\begin{array}{l}2017 \\
\text { (Periode Januari - September 2017) }\end{array}$ & $2,069,149$ \\
\hline
\end{tabular}

Sumber: Kementerian Pariwisata (2017)

Besarnya kebutuhan pasar untuk menukarkan uangnya dengan berbagai kepentingan berbanding lurus dengan banyaknya perusahaan money changer di Jakarta, tetapi tidak sebanding dengan ketersediaan uang kertas asing yang dimiliki masing-masing money changer. Berdasarkan data Bank Indonesia (2016), terdapat 393 perusahaan money changer yang beroperasi di Jakarta. Hal ini dapat memberikan peluang bagi sebuah perusahaan money changer untuk menukarkan mata uang asing dengan perusahaan money changer lainnya dan mendapat keuntungan dari transaksi tersebut.

Sekarang ini, teknologi pertukaran informasi berkembang dengan sangat cepat dan pesat. Banyaknya inovasi yang dilakukan oleh perusahaan semakin memudahkan masyarakat untuk memenuhi kebutuhan dan keinginan mereka. Oleh karena itu, perusahaan money changer pun perlu melakukan sebuah inovasi dalam pelayanannya agar lebih memudahkan dalam melakukan transaksi penukaran mata uang asing dan dapat menghadapi persaingan yang ada.

\section{METODOLOGI PENELITIAN}

Menurut Ibrahim (2009), studi kelayakan bisnis merupakan salah satu pertimbangan dalam mengambil suatu keputusan untuk menolak atau menerima suatu ide bisnis atau proyek berdasarkan aspek-aspek terkait. Selain itu, studi kelayakan bisnis adalah suatu penelitian terhadap aspek-aspek yang mempengaruhi bisnis yang bertujuan untuk mengetahui apakah ide bisnis layak atau tidak untuk dijalankan atau diinvestasikan (Suliyanto, 2010). Kelayakan suatu usaha diukur dari perbandingan antara manfaat dan kerugian yang dihasilkan dari usaha tersebut (Suliyanto, 2010). Dalam perencanaan bisnis penukaran mata uang asing Forrency, aspek-aspek terpilih adalah aspek lingkungan, aspek hukum, aspek teknis dan teknologi, aspek SDM, aspek pemasaran, dan aspek keuangan. Aspek-aspek ini akan dianalisa untuk 
mengetahui apakah perencanaan bisnis penukaran mata uang asing Forrency layak untuk dijalankan atau tidak.

\section{HASIL DAN PEMBAHASAN}

Berikut merupakan hasil dan pembahasan yang diperoleh melalui studi kelayakan bisnis untuk perencanaan penukaran mata uang asing Forrency di Jakarta.

\section{Aspek Lingkungan}

Untuk pemilihan lokasi, kantor Forrency beralamat di JL. Taman Palem Lestari, kecamatan Cengkareng, Jakarta Barat. Lokasi ini sangat strategis karena posisinya yang berbatasan langsung dengan JL. Lingkar Luar dan berdekatan dengan area perumahan yang padat penduduk, banyaknya kantor, restoran, dan pertokoan di sepanjang pinggir jalan, serta di sebelah utaranya juga akan dibangun apartemen dengan fasilitas mal sehingga memiliki pasar yang sangat besar. Keadaan dan kejadian politik global serta setiap kebijakan yang diambil pemerintah Indonesia dapat menyebabkan fluktuasi dan ketidakstabilan dalam nilai kurs sehingga memiliki spread (selisih harga jual dan beli) yang besar. Indonesia juga mengalami keadaan dimana Rupiah mengalami pelemahan terhadap beberapa mata uang dunia, tetapi bisnis penukaran mata uang asing memiliki peluang dengan memanfaatkan spread dalam transaksi jual beli. Selain itu keadaan sosial kota Jakarta yang padat penduduk juga memicu masyarakat untuk sebisa mungkin memanfaatkan waktu secara efektif dan efisien dalam mengejar suatu keperluan tertentu sehingga Forrency selaku perusahaan penukaran mata uang asing melakukan inovasi dengan pelayanan yang dapat dilakukan secara langsung dan online untuk memudahkan masyarakat dalam penukaran mata uang asing. Budaya masyarakat Jakarta yang juga sibuk dengan setiap aktivitas yang dilakukan sehingga membutuhkan waktu untuk beristirahat. Keadaan ini dapat dimanfaatkan dengan berekreasi ke sebuah tempat wisata, baik itu domestik maupun mancanegara. Jika masyarakat berekreasi dengan tujuan mancanegara maka bisnis penukaran mata uang asing merupakan pilihan bisnis yang tepat karena masyarakat membutuhkan mata uang asing untuk dapat bertransaksi di luar.

\section{Aspek Hukum}

Dalam membuat sebuah bisnis perlu selalu berlandaskan dengan hukum. Hal ini juga berlaku bagi perusahaan penukaran mata uang asing. Aspek hukum berkaitan dengan legalitas perusahaan dan pemenuhan izin atau persyaratan yang sesuai dengan peraturanperaturan yang ada. Beberapa surat-surat atau dokumen perlu dilengkapi agar dapat memenuhi persyaratan izin untuk membuka bisnis penukaran mata uang asing. Tabel 2 menunjukkan surat-surat dan dokumen-dokumen yang diperlukan untuk membuat bisnis penukaran mata uang asing menjadi legal.

\section{Tabel 2 Surat-Surat Perizinan Money Changer}

\begin{tabular}{|c|l|l|}
\hline No & \multicolumn{1}{|c|}{ Surat-Surat } & \multicolumn{1}{c|}{ Keterangan } \\
\hline 1 & Akta Pendirian Perusahaan & $\begin{array}{l}\text { Persyaratan data untuk membuat akta } \\
\text { perusahaan dapat dilakukan dengan mudah }\end{array}$ \\
\hline 2 & NPWP & Untuk mendapatkan NPWP cukup mudah \\
\hline 3 & Surat Keterangan Domisili Perusahaan & Pengajuan surat di Kelurahan cukup mudah. \\
\hline 4 & Tanda Daftar Perusahaan (TDP) & $\begin{array}{l}\text { Persyaratan untuk mendapatkan TDP cukup } \\
\text { mudah. }\end{array}$ \\
\hline 5 & $\begin{array}{l}\text { Surat Keputusan (SK) Kehakiman dari } \\
\text { Departemen Hukum dan HAM RI }\end{array}$ & $\begin{array}{l}\text { Persyaratan untuk mendapatkan SK } \\
\text { Kehakiman cukup mudah. }\end{array}$ \\
\hline 6 & Surat Izin Usaha dari Bank Indonesia & $\begin{array}{l}\text { Persyaratan dokumen yang diperlukan untuk } \\
\text { memperoleh izin dari Bank Indonesia }\end{array}$ \\
\hline
\end{tabular}




\section{Aspek Teknis dan Teknologi}

Untuk menganalisa kelayakan aspek teknis dari bisnis diperlukan beberapa penentuan seperti lokasi bisnis dan kebutuhan peralatan. Pada analisis ini lokasi bisnis berada di Jalan Taman Palem Lestari, Jakarta Barat. Di daerah sekitar pada area tersebut terdapat tiga perusahaan money changer yaitu Ricci Valasindo, Sukses Inti Pratama, dan Homeeah Valas. Dengan demikian, Forrency tidak menjadi satu-satunya perusahaan mata uang asing yang menyediakan pelayanan mata uang asing, tetapi dengan inovasi dalam pelayanannya, dimana pelayanan dapat dilakukan secara online melalui aplikasi dan website, menjadikan Forrency sebagai perusahaan dengan konsep pelayanan penukaran mata uang asing yang terbilang baru dimana belum banyak pesaing usaha yang memiliki konsep serupa.

Dalam membuat suatu bisnis juga memerlukan beberapa peralatan sebagai penunjang bagi bisnis tersebut, demikian juga dengan perusahaan money changer. Beberapa peralatan yang dibutuhkan dapat dilihat pada tabel 3

Tabel 3 Perlengkapan Peralatan Kantor

\begin{tabular}{|c|l|c|l|}
\hline No & \multicolumn{1}{|c|}{ Nama } & Jumlah & \multicolumn{1}{|c|}{ Keterangan } \\
\hline 1 & Mesin Hitung Uang & 1 Unit & $\begin{array}{l}\text { Mempermudah untuk menghitung uang } \\
\text { dalam jumlah banyak }\end{array}$ \\
\hline 2 & Brankas Uang & 1 Unit & Meletakkan persediaan mata uang asing \\
\hline 3 & Alat Pendeteksi Valuta Asing & 1 Unit & Memeriksa keaslian uang \\
\hline 4 & Papan Kurs & 1 Unit & $\begin{array}{l}\text { Mempermudah konsumen melihat harga } \\
\text { kurs }\end{array}$ \\
\hline 5 & Telepon & 2 Unit & Menghubungi nasabah maupun karyawan \\
\hline 6 & Jaringan Internet & $\begin{array}{l}\text { Melakukan pembaharuan informasi } \\
\text { terhadap mata uang asing }\end{array}$ \\
\hline 7 & Komputer dan Laptop & 3 Unit & $\begin{array}{l}\text { Memenuhi kebutuhan kantor untuk } \\
\text { administrasi dan penyimpanan data }\end{array}$ \\
\hline 8 & Printer & 1 Unit & \multicolumn{2}{|c|}{} \\
\hline 9 & Televisi LED & 1 Unit & Memantau keadaan pasar melalui berita \\
\hline 10 & Pendingin ruangan (AC) & Unit & Menyejukkan ruangan \\
\hline 11 & Furniture & $\begin{array}{l}\text { Tempat untuk duduk dan bekerja bagi } \\
\text { nasabah dan karyawan }\end{array}$ \\
\hline
\end{tabular}

\section{Aspek SDM}

Aspek SDM perlu dianalisa pada bisnis agar keseluruhan perencanaan SDM dapat dijalan dengan baik. Aspek ini meliputi struktur organisasi perusahaan dan job description. Gambar 1 menunjukkan struktur organisasi perusahaan

\section{Gambar 1 Struktur Organisasi Forrency}

\section{Direktur \\ (Owner)}
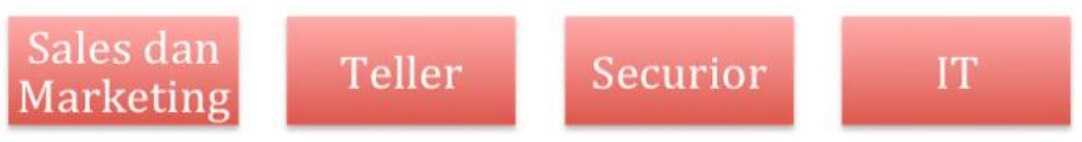

Berikut merupakan job description untuk anggota perusahaan:

Direktur

- Memberikan pendanaan.

- Merencanakan, membantu, mengawasi, dan mengevaluasi sistem manajemen dan kegiatan operasional Forrency.

- Mengambil keputusan yang berhubungan dengan perusahaan. 
Sales dan Marketing

- Merencanakan promosi dan pemasaran produk untuk meningkatkan penjualan.

- Menghubungi dan menawarkan kepada nasabah dan perusahaan tertentu yang membutuhkan mata uang asing.

- Memberikan instruksi kepada securior untuk mengantarkan uang asing kepada nasabah.

- Memberikan pembaharuan informasi atas transaksi yang dilakukan oleh pemasaran kepada teller jika ada nasabah yang ingin mengambil mata uang asing.

- Menerima masukan dan saran tentang pelayanan yang diberikan baik secara langsung maupun secara online.

Teller

- Bertanggung jawab melayani dan menyelesaikan transaksi atas nasabah yang datang ke kantor dari awal transaksi hingga transaksi tersebut selesai.

- Melakukan pemeriksaan dan penghitungan mata uang asing dari dan ke nasabah.

- Melakukan identifikasi, pencocokan, dan konfirmasi bahwa transaksi tersebut sesuai dengan profil nasabah.

- Melakukan pencatatan dan penginputan atas setiap transaksi yang dilakukan ke dalam program.

- Memberikan instruksi kepada securior untuk mengantar uang asing kepada nasabah.

- Melaporkan transaksi yang dinilai mencurigakan kepada pihak legal untuk dilaporkan kepada pihak berwenang.

Securior

- Menerima instruksi dari pemasaran atau teller untuk mengantarkan uang asing kepada nasabah.

- Menghitung kembali uang yang diberikan, apakah sesuai dengan jumlah yang tercatat dalam nota yang akan diantar kepada nasabah.

- Mengkonfirmasi kembali kepada nasabah tentang pesanan yang dilakukan untuk memastikan bahwa benar nasabah tersebut yang memesan mata uang asing untuk diantar.

IT

- Mengembangkan aplikasi yang menolong dalam proses penukaran mata uang asing.

- Mengubah nilai kurs pada aplikasi.

- Mengawasi proses pemesanan yang dilakukan secara online.

- Melakukan pengembangan dalam fitur-fitur untuk aplikasi yang semakin memudahkan nasabah dalam pelayanan.

\section{Aspek Pemasaran}

Untuk menganalisa aspek pemasaran perlu diketahui apakah ada atau tidaknya pasar, kemudian pasar tersebut diidentifikasi menggunakan metode segmenting, targeting, dan positioning. Pada penelitian ini proses segmentasi menggunakan empat faktor yaitu faktor geografis, demografis, psikografi, dan tingkah laku. Setelah melakukan analisa segmentasi maka dilakukan proses targeting dari pasar yang telah tersegmentasi. Berdasarkan proses segmentasi maka didapatkan targeting dari bisnis yaitu warga kota Jakarta yang membutuhkan dan sering menggunakan mata uang asing untuk kepentingan seperti berlibur, pekerjaan, bisnis, dan ibadah. Kemudian dilakukan proses positioning dari perusahaan untuk membentuk image perusahaan di mata konsumen yaitu Forrency sebagai perusahaan jasa penukaran mata uang asing dengan konsep pelayanan yang dapat dilakukan secara langsung maupun online melalui aplikasi dan website dengan penggunaannya yang mudah, cepat, dan nyaman sehinnga calon nasabah dapat dengan yakin untuk membeli produk. 


\section{Aspek Keuangan.}

Analisis aspek keuangan merupakan inti dari sebuah studi kelayakan bisnis. Jika aspek keuangan dari suatu bisnis dikatakan layak maka aspek-aspek lain seakan-akan menjadi tidak terlalu penting. Pada penelitian ini aspek keuangan memiliki penilaian investasi dengan menerapkan dua metode yaitu net present value (NPV) dan payback period. Berikut pada tabel 5 dan 6 adalah tabel penilaian investasi bisnis penukaran mata uang asing Forrency.

Tabel 5 Penilaian Investasi dengan Metode Net Present Value

\begin{tabular}{|c|c|r|}
\hline Tahun & Arus Kas Forrency & \multicolumn{1}{c|}{ Present Value } \\
\hline 0 & 563.360 .000 & Initial Investment \\
\hline 1 & -68.360 .000 & -62.145 .455 \\
\hline 2 & 212.522 .000 & 175.638 .017 \\
\hline 3 & 564.613 .000 & 466.622 .314 \\
\hline 4 & 998.795 .900 & 825.451 .157 \\
\hline 5 & 1.527 .418 .090 & 1.262 .329 .000 \\
\hline 6 & 2.164 .475 .519 & 1.788 .822 .743 \\
\hline \multirow{4}{*}{} & Total & $\mathbf{4 . 4 5 6 . 7 1 7 . 7 7 6}$ \\
\cline { 2 - 3 } & Initial Investment & 563.360 .000 \\
\cline { 2 - 3 } & NPV & $\mathbf{3 . 8 9 3 . 3 5 7 . 7 7 6}$ \\
\hline
\end{tabular}

Tabel 6 Penilaian Investasi dengan Metode Payback Period

\begin{tabular}{|c|r|r|}
\hline Tahun & \multicolumn{1}{|c|}{ Arus Kas } & \multicolumn{1}{c|}{ Arus Kas Kumulatif } \\
\hline 0 & -563.360 .000 & -563.360 .000 \\
\hline 1 & 212.522 .000 & -350.838 .000 \\
\hline 2 & 564.613 .000 & 213.775 .000 \\
\hline 3 & 998.795 .900 & 1.212 .570 .900 \\
\hline 4 & 1.527 .418 .090 & 2.739 .988 .990 \\
\hline 5 & 2.164 .475 .519 & 4.904 .464 .509 \\
\hline \multirow{2}{*}{} & Payback Period & 1,62 \\
\cline { 2 - 3 } & &
\end{tabular}

Berdasarkan Tabel 5 dan 6 maka didapatkan payback period kurang dari lima tahun, yaitu selama 1,62 tahun. Selain itu, bisnis ini juga memiliki NPV lebih besar dari 0 (nol), yaitu Rp. 3.893.357.776 (Tiga Miliar Delapan Ratus Sembilan Puluh Tiga Juta Tiga Ratus Lima Puluh Tujuh Ribu Tujuh Ratus Tujuh Puluh Enam Rupiah). Kedua penilaian ini membuktikan kelayakan keuangan dari bisnis penukaran mata uang asing Forrency, oleh karena itu bisnis ini dikatakan layak secara finansial.

\section{KESIMPULAN DAN SARAN}

Dari keseluruhan pembahasan dan analisis yang telah dilakukan pada bagian-bagian sebelumnya, maka dapat diambil beberapa kesimpulan sebagai berikut:

- Secara lingkungan, penentuan lokasi untuk membangun bisnis telah ditentukan, tetapi perlu untuk tetap memperhatikan keadaan yang sedang terjadi di Indonesia, terutama keadaan politik, ekonomi, sosial, dan budaya.

- Secara hukum, surat dan dokumen yang dibutuhkan untuk membuka bisnis penukaran mata uang asing Forrency mudah dipenuhi, maka aspek hukum dikatakan layak.

- Secara teknis, hal-hal yang diperlukan atau harus dilakukan untuk membuat bisnis penukaran mata uang asing tidak memiliki hambatan berarti. 
- Secara SDM, penentuan struktur oragniasi dan job description tidak memiliki hambatan berarti, sehingga secara aspek SDM dikatakan layak.

- Aspek pemasaran dikatakan layak setelah diketahui adanya pasar dari bisnis yaitu warga kota Jakarta yang membutuhkan mata uang asing untuk suatu keperluan dan strategi yang akan digunakan untuk meraih pasar telah ditentukan.

- Aspek keuangan dikatakan layak berdasarkan perhitungan penilaian investasi yang telah dilakukan. Kelayakan tersebut terdiri dari nilai NPV yang melebihi nol dan payback period selama 1,62 tahun.

Berdasarkan hasil penelitian yang telah dilakukan, maka didapatkan beberapa saran yang diharapkan memperkaya pembaca dalam hal pengetahuan tentang bisnis penukaran mata uang asing, yaitu:

- Memiliki sumber informasi yang akurat sebagai pertimbangan harga kurs.

- Peningkatan dalam pelayanan dengan peningkatan dan penambahan fitur dalam aplikasi agar dapat lebih menarik minat pasar.

- Melakukan survei kepuasan pelayanan untuk mengetahui tentang kualitas pelayanan yang diberikan dan apa yang harus dilakukan untuk menjadi lebih baik.

\section{DAFTAR PUSTAKA}

Bank Indonesia (2016). Peraturan Bank Indonesia Nomor 18/20/PBI/2016 Tentang Kegiatan Usaha Penukaran Valuta Asing Bukan Bank. Retrieved August 7, 2018, from https://www.bi.go.id/id/peraturan/sistempembayaran/Documents/pbi_182016.pdf

Bank Indonesia (2016). Rekapitulasi Keputusan Pemberian Izin Usaha (KPmIU) Penyelenggara Kegiatan Usaha Penukaran Valuta Asing Bukan Bank s.d. Maret 2016. Retrieved November 20, 2018, from http://www.bi.go.id/id/publikasi/lain/lainnya/Contents/Daftar\%20Nama\%20Penyelen ggara\%20KUPVA\%20Bukan\%20Bank\%20per\%20Maret\%202016.pdf

Ibrahim, Y. (2009). Studi Kelayakan Bisnis Edisi Revisi. Jakarta: Rineka Cipta.

Kementerian Pariwisata (2015). Statistik Wisatawan Mancanegara. Retrieved October 20, 2018, from http://www.kemenpar.go.id/userfiles/desember.pdf

Kementerian Pariwisata (2016). Statistik Wisatawan Mancanegara. Retrieved October 20, 2018, from http://www.kemenpar.go.id/userfiles/ 12_\%20Lapbul\%20Desember\%202016.pdf

Kementerian Pariwisata (2017). Statistik Wisatawan Mancanegara. Retrieved October 20, 2018, from Lapbul\%20Sept\%202017_klasik.pdf http://www.kemenpar.go.id/userfiles/

Suliyanto. (2010). Studi Kelayakan Bisnis: Pendekatan Praktis. Yogyakarta: Andi. 
